\title{
Behavioral Activation and Inhibition in Everyday Life
}

\author{
Shelly L. Gable, Harry T. Reis, and Andrew J. Elliot \\ University of Rochester
}

\begin{abstract}
Joint effects of daily events and dispositional sensitivities to cues of reward and punishment on daily positive affect (PA) and negative affect (NA) were examined in 3 diary studies. Study 1 showed that positive events were strongly related to PA but not NA, whereas negative events were strongly related to NA but not PA. Studies 2 and 3 examined how the dispositional sensitivities of independent appetitive and aversive motivational systems, the Behavioral Activation System (BAS) and the Behavioral Inhibition System (BIS), moderated these relationships. Participants in Study 2 with higher BAS sensitivity reported more PA on average; those with more sensitive BIS reported more NA. Also, BIS moderated reactions to negative events, such that higher BIS sensitivity magnified reactions to negative events. Study 3 replicated these findings and showed that BAS predisposed people to experience more positive events. Results demonstrate the value of distinguishing within-person and between-person effects to clarify the functionally independent processes by which dispositional sensitivities influence affect.
\end{abstract}

Extensive research addresses the role of mood and affect in cognition and behavior. Studies of the occurrence of and fluctuations in daily affect provide a logical complement to studies of affective influences on psychological processes, because they can help identify the prevalence and impact of affect in natural experience. Studies of daily affective experience have largely focused on how events, mainly stressors, contribute to affect (e.g., Bolger \& Zuckerman, 1995; Clark \& Watson, 1988; van Eck, Nicolson, \& Berkhof, 1998). However, on any given day, people experience myriad events, some positive and some negative, that influence their moods to varying degrees. The present research focused on the role of two factors-the valence of daily events and dispositional sensitivities to reward and punishment-in everyday affective experience. We asked the general question, how do everyday events and these dispositional tendencies combine to influence day-to-day affect?

Many studies have examined relationships among dispositions and psychological well-being (defined here in terms of daily affect; Diener \& Lucas, 1999). Less, but still substantial, attention has been focused on within-person variability in daily affect. Both kinds of studies are needed. Whereas studies of dispositions provide insights into relatively stable differences among people, studies of within-person variability highlight fluctuations that are salient from people's personal perspective. Although within-person

Shelly L. Gable, Harry T. Reis, and Andrew J. Elliot, Department of Clinical and Social Sciences in Psychology, University of Rochester.

This research was supported by NRSA Predoctoral Fellowship 11766 from the National Institutes of Health. We thank Emory Cowan and John Nezlek for comments on an earlier version of this article.

Correspondence concerning this article should be addressed to Shelly L. Gable, Department of Clinical and Social Sciences in Psychology, Meliora Hall, University of Rochester, Rochester, New York 14627. Electronic mail may be sent to gable@psych.rochester.edu. processes are generally recognized to be statistically independent of between-person processes, the conceptual difference between these levels of analysis is sometimes overlooked (Gable \& Reis, 1999). Daily life may be experienced in within-person terms; that is, mood at a given moment or on a given day may be experienced as better, worse, or the same as mood at the prior moment or on the prior day. In other words, well-being is often evaluated temporally, by comparing present circumstances to the recent past-for example, the hour, day, or month before. Focusing exclusively on either between- or within-person processes may overlook important contributions to psychological well-being provided by the other. Perhaps more important, focusing separately on one or the other ignores interactions between dispositions and environmental factors (Diener, 1996).

Few studies have combined these levels of analysis. In one, Bolger and Schilling (1991) compared two explanations for the relationship between neuroticism and emotional distress: Neuroticism might be associated with greater exposure to stressful events, or it might engender greater reactivity to stressful events that do occur. Their between-persons results indicated that exposure and reactivity accounted for roughly equal proportions of the neuroticism-distress correlation, whereas their within-persons findings gave greater weight to the reactivity explanation. They concluded that the within-persons results may more accurately illumine the distress process because aggregate correlations (i.e., between-person) may arise from unmeasured individual differences correlated with both exposure and reactivity, and because within-person effects better reflect a given episode or moment. They referred to the tendency to equate between- and withinpersons processes as an "ecological fallacy": "it is unwise to assume that correlations between variables defined at the betweenperson level may give us accurate estimates of correlations between the same variables if they were measured within persons over time" (p. 381). The present research builds on their approach by examining daily experiences of affect through the ebb and flow of common, everyday events. 


\section{Reactions to Daily Events}

Major life events have important ramifications for psychological well-being (Holmes \& Rahe, 1967), although these effects tend to be limited to events that occurred during the past three months (Suh, Diener, \& Fujita, 1996). In contrast, other evidence indicates that relatively minor or mundane daily life events are also related to well-being (e.g., Seidlitz \& Diener, 1993; Suls, Green, \& Hillis, 1998). Most of this research has focused on negative events (i.e., stressors). For example, in a 6-week diary study of 166 married couples, Bolger, DeLongis, Kessler, and Schilling (1989) found that daily stressors alone, especially interpersonal conflicts, accounted for up to $20 \%$ of the variance in mood.

Langston (1994) argued that insufficient attention has been paid to positive events, showing that they have an independent effect on psychological well-being, over and above the impact of negative events. Life satisfaction, in fact, was correlated with positive events but not negative events. In a similar vein, Clark and Watson (1988) found that positive events, especially social events, were related to daily positive affect, whereas "irritants" or stressors were correlated with daily negative affect. More recently, in a community sample of men, David, Green, Martin, and Suls (1997) found that positive events predicted positive mood, whereas negative events predicted both negative and positive mood. These and several other studies suggest that the impact of positive and negative events should be differentiated, much as positive and negative affect are considered independent (Berry \& Hansen, 1996; Zautra \& Reich, 1983). Different processes may underlie the associations between events and positive affect than those that link events and negative affect.

The well-documented importance of person-situation interactions (Endler \& Magnusson, 1976) suggests that the impact of events on well-being may be moderated by dispositions (as shown by Bolger and Schilling's, 1991, reactivity results). For example, in a series of studies, Suls and colleagues (e.g., David et al., 1997; Marco \& Suls, 1993; Suls et al., 1998) investigated associations between neuroticism and reactions to daily stressors. Persons scoring high in neuroticism tend to be more reactive to stressors and more distressed by recurrent problems than are persons low in neuroticism, whereas the effect of new problems did not depend on neuroticism. Similarly, van Eck et al. (1998) found that reactions to daily stressors were greater to the extent that persons were high in trait anxiety and perceived stress. Moderation of responses to daily events as a function of dispositions is also demonstrated by research within the person-environment fit tradition. For example, in investigating their concordance model, Moskowitz and Côté (1995) showed that people high on the trait of agreeableness reported more positive moods when they engaged in behaviors consistent with their traits, and more negative moods when they engaged in behaviors contrary to their traits.

In sum, there is evidence that individual differences may moderate relationships among events and well-being. However, research has emphasized dispositions that seem relevant to negative events. Relatively few such dispositions have been studied, and little work has considered the influence of dispositional factors within a comprehensive conceptual system. The present research examined (a) individual differences posited in Gray's (1987) neuropsychological model of motivation and (b) how these differences moderate affective reactions to positive and negative daily events.
Behavioral Inhibition and Behavioral Activation

The existence of two distinct, functionally independent systems for behavioral regulation and motivation-one appetitive and one aversive- has been proposed by several theorists (e.g., Carver, 1996; Diener \& Emmons, 1984; Elliot, 1997; Fowles, 1994; Higgins, 1998; Lang, 1995; Watson, Clark, \& Tellegen, 1988). The present research focused on Gray's (1987) model of emotion, which postulates the existence of separate appetitive and aversive motivational systems, referred to as the behavioral activation system (BAS) and the behavioral inhibition system (BIS), respectively. A major advantage of Gray's model is that it is based on considerable evidence (mostly from animal research) supporting independent neurobiological mechanisms for these systems. The appetitive system (BAS) activates behavior in response to signals of reward and nonpunishment, whereas the aversive system (BIS) inhibits behavior in response to signals of punishment, nonreward, and novelty. Activation of the BAS is associated with feelings of hope and approach behaviors, whereas activation of the BIS is associated with feelings of anxiety and avoidance behaviors (Gray, 1990).

Recent evidence supports both the neurobiological grounding and functional independence of the BIS-BAS systems in humans. Regarding the former, Sutton and Davidson (1997) found that BIS and BAS scores predicted different components of resting prefrontal asymmetry as measured with electroencephalographic (EEG) technology (see also Harmon-Jones \& Allen, 1997). Participants with higher BAS showed more relative left prefrontal activation, whereas those with higher BIS scores showed greater relative right prefrontal activation. Moreover, "prefrontal EEG asymmetry accounted for more than $25 \%$ of the variance in the self-report measure of relative BIS/BAS strength" (Sutton \& Davidson, 1997, p. 204). As for functional independence, Rusting and Larsen (1998b) used the BIS-BAS constructs to predict performance on cognitive tasks and found that BAS was related to performance when stimuli were positive but not negative or neutral. BIS has been used to explain self-regulation and inhibition of prejudiced responses (Monteith, 1993) and differences in procedural learning under conditions of punishment and reward (Corr, Pickering, \& Gray, 1997).

The independence of BIS and BAS as distinct systems representing appetitive and aversive motivation parallels mood research that has identified independent dimensions of positive and negative mood, commonly called Positive Affect (PA) and Negative Affect (NA; Watson, Wiese, Vaidya, \& Tellegen, 1999). Extensive research supports the independence of PA and NA over relatively long (e.g., 3 weeks) and short (e.g., $1 \mathrm{hr}$ ) time periods (e.g., Larson, 1987; Watson, 1988), at least for the moderate levels of affect that constitute the bulk of normal everyday experience (Watson \& Clark, 1994). Cacioppo and Gardner's (1999) recent review similarly concludes that independent biological mechanisms appear likely to regulate experiences of PA and NA (probably because PA and NA had different roles in evolution), one indication of which would be differential predictors of PA and NA elicitation. Meyer and Shack's (1989) two-dimensional model of mood and personality reaches a similar conclusion. In line with Barrett and Russell's (1998) contention that PA and NA represent subcategories of more generally pleasant and unpleasant affect, we use the term $P A$ to refer to active pleasant feelings and $N A$ to refer 
to active unpleasant feelings. This is consistent with Watson et al.'s (1999) suggestion that the terms positive activation and negative activation more accurately represent $\mathrm{PA}$ and NA as measured by the PANAS (Positive and Negative Affect Schedule) measure.

The importance of the BIS-BAS systems for understanding differential experiences of mood and affect stems from the value of relating a neuropsychologically grounded motivational system to the subjective experience of everyday mood. Gray's (1987) model describes each system on three levels: (a) a behavioral level, identifying inputs and outputs that functionally define the system; (b) a neural level, which outlines brain structures and activity patterns that mediate input-output relationships at the behavioral level; and (c) a cognitive level, which describes information processing performed at the neural level. BIS and BAS denote independent systems of response to distinct environmental inputs through separate neural mechanisms, resulting in distinctive affective outputs. Thus, changes in PA may be interpreted as activation of the BAS system by reward-relevant inputs, whereas increases in NA may be interpreted as activation of the BIS system by punishment-relevant inputs (cf. Tellegen, 1985).

Carver and White (1994) created scales to measure individual differences in BIS and BAS sensitivities. Consistent with the above theorizing, BIS predicted higher levels of anxiety among participants told that an unpleasant event would occur midway through an experiment if their performance was poor. On the other hand, BAS sensitivity predicted self-reported happiness among participants told that they would receive a reward for good performance (Carver \& White, 1994, Study 4). Other research, theoretically grounded in Gray's (1987) model but operationalizing BIS and BAS as neuroticism and extraversion, has found similar results. For example, people high in BIS sensitivity (as measured by neuroticism) react more strongly to a laboratory induction of negative mood than do people low on BIS sensitivity, whereas people high in BAS sensitivity (as measured by extraversion) react more strongly to positive mood inductions than do people low in BAS sensitivity (Larsen \& Ketelaar, 1991). However, viewing neuroticism and extraversion as measures of Gray's BIS and BAS is inappropriate because although BIS and BAS appear to be related to neuroticism and extraversion, these traits are clearly not isomorphic (Pickering, Corr, \& Gray, 1998; Rusting \& Larsen, 1997, 1999).

We are aware of no existing research that investigates the relevance of BIS-BAS processes for affective experience from a within-persons perspective. Such research may help account for day-to-day mood variability. Although individual differences in BIS-BAS sensitivity may predict differential reactions to experimental stimuli, real-life affect depends not only on these tendencies but also on reward and punishment opportunities afforded by the natural environment. That is, people with high BIS sensitivity may not experience much anxiety and other negative affects if their environments (by chance or by design) do not present significant BIS-activating events (Carver \& White, 1994; Tellegen, 1985). Similarly, people with high BAS sensitivity may not experience substantial positive affect if their environments do not provide reward-eliciting events to activate the BAS. Thus, the role of BIS and BAS in natural mood variations is unclear. Examining naturally occurring daily events may provide a useful complement to existing laboratory studies.
We examined two general processes by which motivational dispositions may influence daily affect: differential exposure and differential reactivity (Bolger \& Zuckerman, 1995). The differential exposure hypothesis proposes that traits like BIS and BAS may influence tendencies to experience certain types of events. In longitudinal studies of major life events, extraversion was positively related to reports of favorable major events whereas neuroticism predicted reports of unfavorable major events (e.g., Headey \& Wearing, 1989; Magnus, Diener, Fujita, \& Pavot, 1993). Accordingly, people with greater BIS sensitivity may recognize the potential for negative events more readily and may actively avoid such situations (e.g., by attempting less challenging tasks). Similarly, people with greater BAS sensitivity may seek out situations in which positive events are more likely to occur (e.g., approaching an attractive stranger). In contrast, the differential reactivity hypothesis proposes that affect is based largely on reactions to events that the environment offers. Thus, people with high BIS sensitivity may react more strongly to negative daily events, and people with high BAS sensitivity may react more strongly to positive daily events. The differential exposure hypothesis implicates processes in which the person's actions determine what the environment affords, whereas the differential reactivity hypothesis suggests a largely reactive process. The present research was designed to examine these two processes as potential explanations for associations among BIS and BAS dispositions, everyday life experiences, and positive and negative affect.

\section{Summary and Hypotheses for Studies 1-3}

Following Gray's (1987) theorizing, we reasoned that negative events may activate BIS with consequences for negative affect, and that positive events may activate BAS with consequences for positive affect. Consistent with the functional independence of these systems, we expected that negative events would be unrelated to positive affect, and that positive events would be unrelated to negative affect. These processes were examined in terms of individual differences (between-person hypotheses), day-to-day variation (within-person hypotheses), and interactions (i.e., that individual differences in BIS-BAS sensitivities moderate the relationship of daily events to affect).

Within-persons hypotheses:

1. Positive daily events will relate positively to daily PA but will be unrelated to daily NA.

2. Negative daily events will relate positively to daily NA but will be unrelated to daily PA.

Between-persons hypotheses:

3. Higher BAS sensitivity will be associated with higher average levels of PA across days.

4. Higher BIS sensitivity will be associated with higher average levels of NA across days.

5. Higher BAS sensitivity will be associated with greater exposure to positive events.

6. Higher BIS sensitivity will be associated with less exposure to negative events.

Moderator hypotheses:

7. BAS sensitivity will moderate the relationship between positive 
events and PA, such that persons higher in BAS sensitivity will show a stronger relationship between positive events and PA.

8. BIS sensitivity will moderate the relationship between negative events and NA, such that persons higher in BIS sensitivity will show a stronger relationship between negative events and NA.

Hypotheses 5 and 6 test the differential exposure hypothesis, whereas 7 and 8 test the differential reactivity hypothesis.

\section{Study 1}

Study 1 was designed to create a measure of the most important and frequent positive and negative events in college students' lives. We included social and achievement events because these two domains are arguably the most common and pervasive domains of daily activity. Previous measures (e.g., Daily Hassles and Uplifts Scales; Kanner, Coyne, Schaeffer, \& Lazarus, 1981) were not tailored to college samples or do not span multiple domains. Similarly, existing measures of major life events either have concentrated on one type of experience (e.g., stressors) or have not effectively captured the sorts of events that transpire during ordinary, daily life. Because the measure was exploratory, the between-persons and interactive hypotheses were not tested.

\section{Method}

\section{Participants and Procedure}

Participants were 43 undergraduates (19 men and 24 women) who received extra credit toward psychology courses. All measures were programmed onto 3.5-in. diskettes using Micro Experimental Laboratory (MEL; Schneider, 1988), to be run from any PC-based computer. At an initial meeting, participants were given detailed instructions on running the program and a calendar to help them remember to run the program at the end of each day for 7 days. Responses were automatically recorded and stored on the diskettes. Each days' responses were appended to a data file that only the original MEL program could read, so that participants could not view their responses from preceding days, or even preceding questions (Gable \& Nezlek, 1998). Research assistants contacted participants twice during the study to ask about questions or problems. At the conclusion of the study, participants returned their diskettes and took part in a brief exit interview. Nearly all participants reported that the program was "extremely easy" and took 5-10 min. each day.

\section{Measures}

Daily events. A list of 71 events was compiled from the Daily Event Schedule (DES; Butler, Hokanson, \& Flynn, 1994), the Objective/Subjective Event Checklist (Seidlitz \& Diener, 1993), and suggestions from a separate sample of students. Events were coded independently by four raters for valence (positive or negative) and domain (social or achievement). Discrepancies were resolved through discussion. The final list contained 22 positive-social events (e.g., "Went out to eat with a friend/ date"), 16 positive-achievement events (e.g., "Got caught up [or ahead] in course work or duties"), 19 negative-social events (e.g., "A disagreement with a close friend or date was left unresolved"), and 14 negativeachievement events (e.g., "Fell behind in course work or work duties"). On each day, participants rated each event using the following scale: $0=$ did not occur, $1=$ occurred and not important, $2=$ occurred and somewhat important, $3=$ occurred and pretty important, $4=$ occurred and extremely important.

Affect. The PANAS (Watson et al., 1988) was used to measure daily PA and NA. The PANAS consists of 10 positive and 10 negative emotion adjectives and has reported internal consistencies of .90 and .87 , respectively, when used to measure daily affect (Watson et al., 1988). The PA and NA scales are relatively independent; reported correlations for daily ratings are -.05 (between subjects) and -.34 (within subjects; Watson \& Clark, 1997).

\section{Results and Discussion}

We first examined the frequency and importance of events. Six events were dropped because of redundancy with other items, reported ambiguity, or very low frequency of occurrence, resulting in a 65 -item measure comprising 21 positive-social, 15 positiveachievement, 18 negative-social, and 11 negative-achievement events. To compute event frequencies, if a participant reported that the event occurred, the event received a score of 1 , regardless of rated importance. Thus, the frequency score for each event was either 0 (did not occur) or 1 (did occur). The total number of events that occurred each day in each of the four categories was then computed. The mean importance rating for each of the four event types was computed by summing all responses in a category (ranging from 0 to 4 ) and dividing by the number of possible events in that category. Therefore, the importance variable reflects the frequency of events weighted by their reported importance. On average, participants reported 7.2 positive-social, 4.2 positiveachievement, 2.3 negative-social, and 2.8 negative-achievement events per day. Average importance ratings for each category were $0.97,0.75,0.28$, and 0.66 , respectively.

Traditional analysis of variance methods assume independence of observations, an assumption that is clearly violated when the same individual completes the same measures repeatedly over several days. The present data represented a two-level model and were analyzed using Hierarchical Linear Modeling (HLM) techniques (HLMwin v.4.03; Bryk, Raudenbush, \& Congdon, 1996). HLM simultaneously addresses both levels in a hierarchically nested data set, which, in this case, was days nested within persons. HLM provides independent estimates of the relationships among constructs at the lower level (within persons) and models them at the upper level (between persons) as a random effect using maximum likelihood estimation. A series of HLM equations was constructed to examine relationships between daily affect and daily events-the within-person hypotheses.

Because the average within-person correlation between PA and NA was $-.14, p<.05,{ }^{1}$ PA was included in the equation predicting NA, and NA was included in the equation predicting PA. This had the effect of partialing out the small amount of shared variance and ensuring that relationships found between PA and events were independent of NA (and vice versa). The day-level (lower level) equation predicted NA from the four event importance means using the following equation:

$$
\begin{aligned}
\mathrm{NA}_{i j}= & b_{0 j}+b_{1 j}\left(\mathrm{POS} / \mathrm{SOC}_{i j}\right)+b_{2 j}\left(\mathrm{POS} / \mathrm{ACH}_{i j}\right) \\
& +b_{3 j}\left(\mathrm{NEG} / \mathrm{SOC}_{i j}\right)+b_{4 j}\left(\mathrm{NEG} / \mathrm{ACH}_{i j}\right) \\
& +b_{5 j}(\mathrm{PA})+r_{i j}
\end{aligned}
$$

\footnotetext{
${ }^{1}$ The average within-person correlation between PA and NA was calculated by computing an $r$ for each person across the 7 days of data and then converting them to Fisher's $z^{\prime}$ values. These $z^{\prime}$ values were then averaged and converted back to standard Pearson's $r$. The $z^{\prime}$ values were meta-analyzed to determine the significance level following procedures outlined by Rosenthal and Rosnow (1991). The magnitude and direction of the within-person correlation is similar to results from prior research (e.g., Watson \& Clark, 1997).
} 
Table 1

Relationships Between Daily Measures of Affect and Daily Events: Study 1

\begin{tabular}{|c|c|c|c|c|c|}
\hline Measure & Positive-social & Positive-achievement & Negative-social & Negative-achievement & Affect \\
\hline \multicolumn{6}{|l|}{ Negative affect (NA) } \\
\hline Event importance & $.09(.08)$ & $.02(.07)$ & $.55^{* *}(.12)$ & $.22 * *(.06)$ & $-.15^{\mathrm{a}, *}(.06)$ \\
\hline Event frequency & $.01(.01)$ & $.00(.01)$ & $.07 * *(.02)$ & $.04 *(.02)$ & $-.14^{\mathrm{a}, *}(.06)$ \\
\hline \multicolumn{6}{|l|}{ Positive affect (PA) } \\
\hline Event importance & $.43 * *(.08)$ & $.42 * *(.07)$ & $.13(.14)$ & $-.11(.08)$ & $-.19^{\mathbf{b}, *}(.07)$ \\
\hline Event frequency & $.06 * *(.01)$ & $.07 * *(.01)$ & $.01(.02)$ & $-.03(.02)$ & $-.19^{b *}(.07)$ \\
\hline
\end{tabular}

Note. Numbers outside of parentheses are unstandardized HLM coefficients; numbers in parentheses are standard errors. Coefficients in bold are significant. The intercept for the NA equations was 1.78, and the intercept for the PA equations was 2.91 .

${ }^{\mathrm{a}}$ Relation with PA. ${ }^{\mathrm{b}}$ Relation with NA.

$* p<.05$. ${ }^{* *} p<.01$.

where $b_{0 j}$ refers to the intercept (i.e., the person's NA on an average day); $b_{1 j}$ to $b_{4 j}$ represent maximum likelihood estimates of the population slopes relating NA to each of the four event categories, $b_{5 j}$ represents the population slope for daily PA, $r_{i j}$ represents error, POS refers to positive, SOC refers to social, $\mathrm{ACH}$ refers to achievement, and NEG refers to negative. Event category ratings (e.g., $\mathrm{POS} / \mathrm{SOC}_{i j}$ ) were centered around each participant's mean and, therefore, represent the degree to which rated importance on the $i$ th day deviated from their average importance rating in that category. Thus, person $j$ 's NA on the ith day is predicted from his or her average NA, positive-social events importance rating (on the $i$ th day) weighted by its coefficient $\left(b_{1 j}\right)$, positiveachievement events importance rating weighted by its coefficient $\left(b_{2 j}\right)$, negative-social events importance rating weighted by its coefficient $\left(b_{3 j}\right)$, negative-achievement events importance rating weighted by its coefficient $\left(b_{4 j}\right)$, and error. Person-level effects were estimated as follows:

$$
\begin{aligned}
& b_{0 j}=g_{00}+u_{0 j} \\
& b_{1 j}=g_{10} \\
& b_{2 j}=g_{20} \\
& b_{3 j}=g_{30} \\
& b_{4 j}=g_{40} \\
& b_{5 j}=g_{50},
\end{aligned}
$$

where $g_{00}$ in Equation 2a represents the sample-wide day-level intercept, and $u_{0 j}$ is residual variance of the intercepts between persons (a random effect). Because event variables were centered around the person's own mean, the intercept $g_{\infty}$ represents the level of NA that an average person reported on days that they experienced their average event importance in each category. The $b_{1 j}$ in the lower level equation has a corresponding component in the upper level model (Equation $2 b$ ), where $g_{10}$ represents the average slope for positive-social events across persons. Equations for the remaining three event category slopes (Equations 2c, 2d, and $2 e)$ are analogous. Finally, $b_{5 j}$ has a corresponding component in the upper level model (Equation 2f) where $g_{50}$ represents the average slope for PA across persons. Estimating six random effects is not feasible in this data set; therefore, the random effects for the slopes were set to zero. Separate but analogous models were used to calculate PA from the four event importance categories (with
NA as a covariate), NA from the four event frequency categories (with PA as a covariate), and PA from the four event frequency categories (with NA as a covariate).

Table 1 reports maximum likelihood estimates relating the four event categories to NA and PA. For example, the coefficient for importance of negative-social events and NA (first row of numbers, third column in table) can be interpreted as follows: Each unit increase in negative-social events (i.e., reporting negative-social events on that day that are one unit more negative than one's own average) was associated with a 0.55 unit increase in NA on that day, controlling for the other three event categories and PA. The results show, as predicted, that negative-social and achievement events (frequency and importance ratings) were significantly and positively related to daily NA, whereas positive-social and achievement events were unrelated to daily NA. On the other hand, positive-social and achievement events (frequency and importance ratings) were significantly and positively related to daily PA, but negative-social and achievement events were not related to PA. On days that people experienced more positive events they also reported more PA, but NA was unaffected. On days that people reported more negative events they experienced more NA, but their PA was unaffected. Daily NA and PA were significantly and negatively related (far right column of Table 1 ). ${ }^{2}$

Study 1 provided support for the hypothesized within-person relationships between events and affect. Positive events were associated with changes in daily positive affect, whereas negative events were associated with changes in daily negative affect. Moreover, positive affect did not decrease significantly on days that more negative events occurred, and negative affect did not decrease on days that more positive events occurred. Information on the frequency of occurrence of various types of events was used to construct a briefer daily events measure for Studies 2 and 3.

\section{Study 2}

To test the between-person and interactive hypotheses, Study 2 measured BIS and BAS dispositions. Participants described events and rated their positive and negative affect for 14 days.

\footnotetext{
${ }^{2}$ The models were also run omitting PA from the model predicting NA and NA from the model predicting PA. The results were parallel.
} 


\section{Method}

\section{Participants and Procedure}

Participants were 86 undergraduates ( 35 men and 51 women) who received extra credit toward psychology courses. As in Study 1, participants received instructions from a research assistant, who then contacted participants via phone or E-mail approximately every 5 days throughout the 14 days of the study. In a brief exit questionnaire administered after the diskette had been handed in, $98 \%$ of the participants reported that the program was easy and had taken no more than $10 \mathrm{~min}$ each day.

As in Study 1, data were collected with the MEL software package. One program was run only on the first day of the study and administered the BIS-BAS scale. A second program administered the affect and daily events measures and was run on all 14 days. In addition, and without participants' knowledge, the daily program automatically recorded the date and time of the entry in order to obtain an objective record of compliance with the diary schedule. Litt, Cooney, and Morse (1998) reported that participants in their signal-contingent study verbally reported $79 \%$ compliance (i.e., completing a report on time when signaled). However, extensive debriefing of a subset of individuals revealed that more than $70 \%$ of the sample delayed recording at least once a day (and up to five times a day). Therefore, we sought to verify compliance with the daily sampling protocol.

\section{Measures}

BIS-BAS. Carver and White's (1994) 20-item measure was used to assess individual differences in BIS and BAS sensitivities. A single unidimensional scale consisting of 7 items reflecting BIS sensitivity has a reported reliability $(\alpha)$ of .74 (Carver \& White, 1994). BAS sensitivity is based on 13 items that comprise three subscales. The 5-item RewardResponsiveness subscale describes positive responses to the occurrence of a reward and has reported reliability ( $\alpha$ ) of .73 . The 4-item Drive subscale indexes the willingness to approach positive outcomes ( $\alpha$ is reported as .76). The 4-item Fun Seeking subscale reflects the willingness to try new things ( $\alpha$ is reported as .66). Because all three subscales were relevant to our conceptualization of BAS dispositions, we combined all 13 items into a total BAS score ( $\alpha=.86$ for BAS, and $\alpha=.85$ for BIS in the present study). Jorm et al. (1999) reported that the three BAS subscales constituted a single factor reflecting behavioral activation in their factor analysis of data from over 2,700 adults. BIS scores were essentially independent of BAS scores ( $r=.06$; Jorm et al., 1999), consistent with Gray's (1987) theorizing. ${ }^{3}$

Daily measures. The 20-item PANAS (Watson et al., 1988) was again used to assess daily PA and NA with instructions indicating the time frame of "how you felt today." Daily events were measured with a 36-item subset from Study 1, selected for regular frequency and importance in that study, consisting of 17 positive events ( 9 social and 8 achievement) and 19 negative events ( 9 social and 10 achievement). Participants rated whether or not the event had occurred and, if it had, its importance, using the same scale as in Study 1. Frequency and mean importance scores were tabulated as in Study 1. The analyses combine social and achievement events into overall positive and negative event categories for three reasons: (a) Social and achievement events had very similar relationships to PA and NA in Study 1, as in prior research (e.g., Marco \& Suls, 1993); (b) we had no reason to hypothesize that BIS and BAS would relate differently to, nor interact differently with, social and achievement events; and (c) for maximum likelihood estimation, it is desirable to reduce the number of lower level predictor terms to create a more parsimonious and stable model.

\section{Results}

\section{Compliance and Descriptive Data}

The computer-generated date-time stamps indicated substantial problems in the timing of participants' reports. Records were
Table 2

Means and Standard Deviations for Daily Variables: Studies 2 and 3

\begin{tabular}{lllllll}
\hline & \multicolumn{2}{c}{ Study 2 } & & \multicolumn{2}{c}{ Study 3 } \\
\cline { 2 - 3 } \cline { 6 - 7 } \multicolumn{1}{c}{ Measure } & $M$ & $S D$ & & $M$ & $S D$ \\
\hline Daily affect & & & & \\
$\quad$ PA & 3.06 & 0.81 & & 2.82 & 0.84 \\
NA & 1.72 & 0.78 & & 1.73 & 0.72 \\
Daily event frequency & & & & & \\
$\quad$ Positive events & 6.34 & 3.22 & & 7.03 & 2.98 \\
$\quad$ Negative events & 4.30 & 3.74 & & 4.86 & 3.32 \\
Daily event importance & & & & \\
$\quad$ Positive events & 1.13 & 0.62 & & 1.13 & 0.58 \\
$\quad$ Negative events & 0.62 & 0.59 & 0.61 & 0.48 \\
\hline
\end{tabular}

Note. For Study 2: $n=655$ days from $n=50$ participants. For Study 3: $n=782$ days from $n=155$ participants. $\mathrm{PA}=$ positive affect; $\mathrm{NA}=$ negative affect.

coded as delayed when two or more entries were completed within $10 \mathrm{hr}$ of each other. This occurred most often when participants failed to make an entry on one day and then completed two entries on the following day. The validity of daily sampling methods and their ability to portray naturally occurring processes hinges on compliance with study protocols (Reis \& Gable, 2000). Participants who recorded entries late may have relied on retrospection, which may introduce bias, to complete their entries. Also, simultaneous recordings may decrease the amount of dayto-day variability. Therefore, participants who recorded more than 3 days out of 14 in a nontimely manner were considered noncompliant. Data from 36 participants who met this criterion were dropped from the sample. The final sample used in all subsequent analyses consisted of 50 participants (16 men and 34 women) who reported a total of 655 days, an average of 13.1 days per person. ${ }^{4}$

Means and standard deviations for the day-level measures are presented in Table 2. Ordinary Least Squares (OLS) correlations were computed using the same averaging procedure as in Study 1 (see Footnote 1). Daily PA and NA were moderately correlated, $r=-.32, p<.001$. Correlations for the frequencies and importance ratings of positive and negative events were nonsignificant (for event frequencies, $r=-.06$; for event importance ratings, $r=$ $-.16)$.

\footnotetext{
${ }^{3}$ The correlations between BIS and BAS scores in the present research were also nonsignificant ( $r=.22$ and .12 in Studies 2 and 3, respectively).

${ }^{4}$ This cutoff seemed reasonable to minimize the impact of retrospection while retaining as many cases as possible. We chose to eliminate noncompliant participants from the sample as opposed to eliminating only invalid days, because the 36 noncompliant individuals provided repeated multiple entries. For example, 22 noncompliant participants entered 5 or more "days" during one session at the computer. We conducted $t$ tests to compare the compliant and noncompliant groups on the dispositional measures. The two groups did not differ significantly on BIS or BAS. A chi-square test indicated that men were marginally more likely to be noncompliant than women were, $\chi^{2}(1)=3.74, p<.06$. An alternative method, eliminating only invalid days, was used in Study 3.
} 


\section{BIS-BAS Sensitivities, Events, and Affect}

As in Study 1, the data set was hierarchically nested, with days nested within persons, and HLM was used to examine the hypotheses. Unlike Study 1, upper level terms to represent BIS and BAS were included. Once again NA was partialed from the equation predicting PA, and PA was partialed from the equation predicting NA. The lower level (within-person) equation for NA was

$$
\begin{aligned}
\text { NA }_{i j}= & b_{0 j}+b_{1 j}\left(\mathrm{PA}_{i j}\right)+b_{2 j}\left(\text { POSITIVE EVENTS }_{i j}\right) \\
& +b_{3 j}\left(\text { NEGATIVE EVENTS }_{i j}\right)+r_{i j} .
\end{aligned}
$$

The upper level (between-person) equation for NA was

$$
\begin{aligned}
& b_{0 j}=g_{00}+g_{01}(\mathrm{BIS})_{j}+g_{02}(\mathrm{BAS})_{j}+u_{0 j} \\
& b_{1 j}=g_{10}+u_{1 j} \\
& b_{2 j}=g_{20}+u_{2 j} \\
& b_{3 j}=g_{30}+g_{31}(\mathrm{BIS})+u_{3 j} .
\end{aligned}
$$

In the lower level model, $b_{0 j}$ refers to the intercept (average NA, on an average day), $b_{1 j}$ represents the slope between PA and NA, $b_{2 j}$ is the slope between positive events and NA, $b_{3 j}$ is the relationship between negative events and NA, and $r_{i j}$ is error, for each person. Each lower level term has a corresponding upper level equation (Equations 4a-4d) in which each of the lower level terms was calculated as a function of the entire sample and error $(u)$. BIS and BAS were predicted to moderate the intercept $\left(b_{0_{j}}\right)$, and BIS was predicted to moderate the slope between negative events and NA $\left(b_{3 j}\right)$. The lower level (Equation 5) and upper level (Equations $6 a-6 d)$ equations predicting PA paralleled the NA equations:

$$
\begin{aligned}
& \mathrm{PA}_{i j}=b_{0 j}+b_{1 j}\left(\mathrm{NA}_{i j}\right)+b_{2 j}\left(\mathrm{POSITIVE} \mathrm{EVENTS}_{i j}\right) \\
&+b_{3 j}\left(\mathrm{NEGATIVE} \mathrm{EVENTS}_{i j}\right)+r_{i j} \\
& b_{0 j}=g_{00}+g_{01}(\mathrm{BIS})_{j}+g_{02}(\mathrm{BAS})_{j}+u_{0 j} \\
& b_{1 j}=g_{10}+u_{1 j} \\
& b_{2 j}=g_{20}+g_{21}(\mathrm{BAS})+u_{2 j} \\
& b_{3 j}=g_{30}+u_{3 j} .
\end{aligned}
$$

Equations 5 and 6 show that daily PA was predicted from daily NA, daily positive events, daily negative events, BIS, and BAS. Specifically, we tested whether BIS and BAS predicted average daily PA ( $b_{0 j}$, the intercept), and whether BAS moderated the slope between positive events and PA. ${ }^{5}$ Slopes were modeled as random effects (i.e., $u$ s were included in the upper level equations). Following recommendations by Bryk and Raudenbush (1992), we treated effects that did not have a significant random component as fixed (i.e., random error components [us] were dropped from the equation). For simplicity we used $z$ scores for BIS and BAS; therefore, a unit is equivalent to a standard deviation.

The within-persons hypotheses-how events and affect covary-are tested by the coefficients $b_{2 j}$ and $b_{3 j}$. The betweenpersons hypotheses-whether BIS and BAS predicted average levels of PA and NA-are tested by the terms $g_{01}$ and $g_{02}$. The interaction hypotheses-whether BIS and BAS moderated relationships between events and affect-are tested by the coefficients $g_{31}$ in Equation $4 d$ and $g_{21}$ in Equation $6 c$. For these and all subsequent analyses we focused on importance ratings as opposed to frequencies for presentational simplicity and also because frequency counts imply that all events are equally important. (Study 1 showed considerable variability in rated importance between events, and importance ratings for the same type of event often varied from day to day.) Models predicting NA and PA using event frequency, instead of importance, produced parallel results (i.e.; coefficients were in the same direction, and significant coefficients remained significant). ${ }^{6}$

The top half of Table 3 shows results of Equations 3 and 4 predicting NA. In the column labeled "Intercept" on the row marked "Lower level (day)," 1.72 represents the average level of NA reported by people with average BIS and BAS scores on an average day (i.e., with average $P A$, average positive and negative events). Upper level effects in this column indicate that a person one standard deviation above the mean on BIS experienced 0.23 $(p<.01)$ more NA each day than a person of average BIS sensitivity, supporting the between-person hypothesis. Thus, high BIS participants (one standard deviation above the mean) had an average intercept of $1.95(1.72+0.23)$. As expected, the BAS coefficient of 0.10 was not significant, indicating that BAS sensitivity did not predict average NA.

The coefficient of -0.04 indicates that daily positive events did not significantly contribute to NA, whereas the coefficient for negative events $(0.63, p<.001)$ shows that daily negative events significantly predicted NA, as hypothesized. The latter coefficient indicates that a one-unit increase (from one's personal average) of negative event importance corresponded to a 0.63 increase in daily NA. The BIS coefficient of $0.39(p<.01)$ for the Negative events column indicates that the moderator hypothesis was supported. The higher one's BIS score, the more reactive one was to negative events. For example, someone one standard deviation above the BIS mean had an NA-negative events slope of $1.02(0.39+0.63)$, whereas the comparable slope for someone one standard deviation below the mean was only 0.24 . The coefficient in the far right column $(-0.09)$ indicates that daily PA covaried slightly with daily NA: On days people experienced a unit increase in PA, they reported a 0.09 decrease in NA.

In sum, all three hypotheses were supported for NA. Daily NA covaried with daily negative events. People high on BIS experienced significantly more daily NA on average, and they were more reactive to negative events when they occurred. Those with high BIS had higher levels of NA on days they reported more negative events, whereas those who had low BIS did not report much of an increase in NA when they had more than their average share of negative events.

Results for Equations 5 and 6, predicting daily PA, are presented in the bottom half of Table 3. Consistent with our within-person hypothesis, PA was predicted significantly by positive events. Unexpectedly, negative events also covaried with PA. People

\footnotetext{
${ }^{5}$ The "crossover" terms that were not hypothesized (e.g., BIS as a moderator of the PA-positive events slope, BAS as a moderator of the PA-positive events slope) were not represented in the equations. Supplementary analyses that included these terms revealed that all were nonsignificant and almost always very close to zero.

${ }^{6}$ Copies of these results are available from Shelly L. Gable on request.
} 
Table 3

Predicting Daily Negative Affect (NA) and Positive Affect (PA) From the Mean Importance of Daily Events and Behavioral Inhibition System (BIS) and Behavioral Activation System (BAS): Study 2

\begin{tabular}{|c|c|c|c|c|c|c|c|c|}
\hline \multirow[b]{2}{*}{ Effect } & \multicolumn{2}{|c|}{ Intercept } & \multicolumn{2}{|c|}{ Positive events } & \multicolumn{2}{|c|}{ Negative events } & \multicolumn{2}{|c|}{ Affect } \\
\hline & Coefficient & $p$ & Coefficient & $p$ & Coefficient & $p$ & Coefficient & $p$ \\
\hline \multicolumn{9}{|l|}{ Results for NA } \\
\hline $\begin{array}{l}\text { Lower level (day) } \\
\text { Upper level (person) }\end{array}$ & 1.72 & & -.04 & $n s$ & .63 & $<.001$ & $-.09^{a}$ & $<.05$ \\
\hline BIS & .23 & $<.01$ & & & .39 & $<.01$ & & \\
\hline BAS & .10 & $n s$ & & & & & & \\
\hline \multicolumn{9}{|l|}{ Results for PA } \\
\hline $\begin{array}{l}\text { Lower level (day) } \\
\text { Upper level (person) }\end{array}$ & 3.05 & & .50 & $<.001$ & -.17 & $<.05$ & $-.22^{b}$ & $<.01$ \\
\hline BIS & -.16 & $<.05$ & & & & & & \\
\hline BAS & .18 & $<.05$ & .04 & $n s$ & & & & \\
\hline
\end{tabular}

Note. The lower level effects are the main effects for the lower level variable. The upper level effects represent the upper level main effect and interaction effects. BIS and BAS are $z$ scores. Blanks indicate that the effect was not hypothesized and therefore not represented in the equation. See text for interpretation of coefficients. Significant coefficients (based on $t$ tests) are in bold.

${ }^{a}$ Relation with PA. ${ }^{b}$ Relation with NA.

reported higher PA on days they had more positive events and fewer negative events. Because the effect of negative events was not predicted (and was inconsistent with results of Study 1), we compared the magnitude of the positive and negative event coefficients, which revealed that positive events had a significantly stronger relationship with PA than did negative events, $\chi^{2}(1)=28.34, p<.001 .^{7}$

The upper level effects in Table 3 indicated that both BIS and BAS significantly predicted average level of PA. People higher on BIS reported less average PA, and people higher on BAS reported more average PA. BAS failed to significantly moderate the slope between positive events and PA, contrary to the reactivity hypothesis.

\section{Occurrence of Positive and Negative Events}

Hierarchical linear models were constructed to examine whether participants with different BIS-BAS sensitivities experienced more or less daily events, on average-the differential exposure hypothesis. This is a strictly between-persons question and was tested with the following model, using both event importance and frequency data. For negative events the lower level equation was

$$
\text { Negative events } s_{i j}=b_{0 j}+r_{i j} \text {. }
$$

The upper level equation was

$$
b_{0 j}=g_{00}+g_{01}(\mathrm{BIS})+g_{02}(\mathrm{BAS})+u_{0 j},
$$

where the occurrence of negative events was predicted as a function of personality dispositions (BIS and BAS). A parallel model tested the effect of BIS and BAS on positive events.

BIS did not predict importance or frequency of negative events ( 0.10 and 0.47 , respectively; $p s>.15$ ), and BAS did not predict importance or frequency of positive events $(0.08$ and 0.13 , respectively; $p s>.15$ ). Thus, the differential exposure hypothesis was not supported. Also, there were no crossover effects; that is, BIS did not relate to positive events nor did BAS relate to negative events.

\section{Discussion}

Results of Study 2 supported most of our hypotheses and generally demonstrated the expected differentiation of appetition-PA and aversion-NA. Within-persons, daily negative events predicted daily NA, and daily positive events predicted daily PA. Both between-persons hypotheses were supported: BIS sensitivity predicted average NA, and BAS sensitivity predicted daily PA. The moderator (differential reactivity) hypothesis was supported for BIS-persons with higher BIS scores reacted more strongly in terms of NA to negative events-but not for BAS. There were also some unexpected findings: Negative events covaried with daily PA, and BIS predicted average daily PA. The differential exposure hypothesis relating BIS and BAS to the occurrence of events was not supported. We discuss these findings following Study 3 .

A disturbing finding of Study 2 was that $42 \%$ of participants deviated from the daily diary schedule to a fairly extensive degree (see Footnote 4). Our strong hunch is that diary studies rarely verify the actual time of data completion with an objective source (such as a computer clock), even though timing is a critical methodological rationale for these procedures (Reis \& Gable, 2000). Although we have no way of knowing, we do not believe the level of noncompliance in Study 2 was unique to our methods or sample; minimally, the rate of noncompliance is similar to that reported by Litt et al. (1998), who used electronic beepers that signaled adult participants when to complete paper-and-pencil reports. The possibility that this problem may be pervasive in diary studies suggests that researchers should take steps to ensure the timeliness of diaries. One such strategy is reminiscent of the

\footnotetext{
${ }^{7}$ The chi-square test of the difference between two coefficients in HLM is equivalent to a planned comparison. For this test, the positive and negative event coefficients were both assigned a +1 contrast code, because the signs of the actual coefficients were opposite. Therefore, magnitude and direction were unconfounded, and the chi-square tests differences were in magnitude only; i.e., $H_{0}:[+1$ (positive event coefficient) $]+[+1$ (negative event coefficient) $]=0$.
} 
Table 4

Predicting Daily Negative Affect (NA) and Positive Affect (PA) From the Mean Importance of Daily Events and Behavioral Inhibition System (BIS) and Behavioral Activation System (BAS): Study 3

\begin{tabular}{|c|c|c|c|c|c|c|c|c|}
\hline \multirow[b]{2}{*}{ Effect } & \multicolumn{2}{|c|}{ Intercept } & \multicolumn{2}{|c|}{ Positive events } & \multicolumn{2}{|c|}{ Negative events } & \multicolumn{2}{|c|}{ Affect } \\
\hline & Coefficient & $p$ & Coefficient & $p$ & Coefficient & $p$ & Coefficient & $p$ \\
\hline \multicolumn{9}{|l|}{ Results for NA } \\
\hline $\begin{array}{l}\text { Lower level (day) } \\
\text { Upper level (person) }\end{array}$ & 1.74 & & .02 & $n s$ & .70 & $<.001$ & $-.08^{\mathrm{a}}$ & $<.05$ \\
\hline $\begin{array}{l}\text { BIS } \\
\text { BAS }\end{array}$ & $\begin{array}{r}.13 \\
-.07\end{array}$ & $\begin{array}{l}<.01 \\
n s\end{array}$ & & & .13 & $<.05$ & & \\
\hline Results for PA & & & & & & & & \\
\hline $\begin{array}{l}\text { Lower level (day) } \\
\text { Upper level (person) }\end{array}$ & 2.79 & & .57 & $<.001$ & -.11 & $n s$ & $-.11^{b}$ & $<.05$ \\
\hline BIS & -.04 & $n s$ & & & & & & \\
\hline BAS & .15 & $<.01$ & -.02 & $n s$ & . & & & \\
\hline
\end{tabular}

Note. The lower level effects are the main effects for the lower level variable. The upper level effects represent the upper level main effects and interaction effects. BIS and BAS are $z$ scores. Blanks indicate that the effect was not hypothesized and therefore not represented in the equation. See text for interpretation of coefficients. Significant coefficients (based on $t$ tests) are in bold.

${ }^{\text {a }}$ Relation with PA. ${ }^{b}$ Relation with NA.

"bogus pipeline" procedure: Nezlek and Plesko (in press) observed greater compliance when participants completed daily diaries twice a week and were told that the researchers would know when their forms had been completed. Noncompliance is an obvious and substantial limitation of Study 2; thus, we felt it essential to replicate the study using a procedure to increase and verify compliance.

\section{Study 3}

\section{Method}

Participants in Study 3 were 155 undergraduates (57 men and 98 women) who received extra credit toward psychology coursework. At an introductory session, participants completed the trait BIS and BAS measures. Approximately 6 weeks later, they were given seven booklets containing the daily measures, one for each night of the week. Booklets contained the same measures as in Study 2 (daily PANAS and the 36-item daily events measures), except that they were printed on paper instead of programmed onto diskettes. To bolster and verify compliance with the diary schedule, participants were told to return completed diaries early the next day at a table located in the student union or before class (on class days). As an incentive, whenever participants handed in a booklet on time, they received a lottery ticket for prizes to be raffled after the study. Only booklets returned on time were treated as valid and retained in the data set. In Study 2 we discarded all 14 days of a participant's data if he or she showed a pattern of noncompliance. However, in Study 3, we retained all 155 participants in the final sample and only discarded days that were not returned on time. Participants completed 782 days on time, an average of 5.1 days per person. ${ }^{8}$

\section{Results}

Means and standard deviations, presented in Table 2, were nearly identical to those obtained in Study 2 . The average withinperson daily PA-NA correlation was again moderate, $r=-.21$, $p<.01$ (see Footnote 1). Correlations between positive and negative event frequencies $(r=.01)$ and positive and negative event importance ratings $(r=-.08)$ were nonsignificant. Finally, BIS and BAS were not significantly correlated $(r=.12, n s)$. As in
Study 2 , for presentational simplicity, we report analyses using the event importance ratings. Also as in Study 2, models predicting NA and PA using event frequency, instead of importance were run, and the results were parallel with one exception (see below).

\section{BIS-BAS Sensitivities, Events, and Affect}

The same HLM equations described for Study 2 were tested in this study. Table 4 shows that the results of the two studies were very similar. First, regarding the between-persons hypotheses, BIS significantly predicted average NA, such that people high on BIS reported more NA on average. BAS significantly predicted higher average PA. However, in contrast to Study 2, but more in line with our hypotheses, BIS did not significantly predict average PA $(b=$ $-0.04, t<1, n s$ ).

The day-level results in Study 3 replicated the Study 2 findings. In fact, most of the day-level coefficients were very similar. Negative events covaried significantly with $\mathrm{NA}$, and positive events covaried significantly with PA. In contrast to Study 2 , the crossover effect of negative events on PA was not significant. However, when event frequencies were used instead of importance ratings, the crossover effect of negative events on PA was significant $(-0.02, p<.05)$, consistent with Study 2 .

Finally, BIS again significantly moderated the slope between negative events and NA $(b=0.13, p<.05)$. On days people experienced higher than average negative events, high-BIS individuals revealed greater increases in NA than low-BIS individuals. In other words, high-BIS individuals had higher NA on average

\footnotetext{
${ }^{8}$ Two nontraditional students over the age of 35 were dropped from the sample because the events measure, developed and validated on a standardage college sample, was likely to be inappropriate for their daily activities. Including these two participants produced nearly identical results (i.e., coefficients and significance levels remained virtually the same). We also repeated all analyses with a sample that included diaries turned in as late as $24 \mathrm{hr}$ past their deadline ( $n=923$ days). These results paralleled those reported in the text (i.e., coefficients and significance levels were virtually identical).
} 
and were more reactive to negative events. Also consistent with the findings of Study 2, BAS did not significantly moderate the slope between positive events and $P A$.

\section{Occurrence of Positive and Negative Events}

Given the higher level of verified compliance with the sampling scheme in this study, the differential exposure hypothesis was reexamined. We first looked at the occurrence of negative events using Equations 7 and 8 from Study 2. Consistent with Study 2, BIS did not predict the frequency or importance of daily negative events $(b s=0.12$ and 0.05 , respectively, both $n s$ ). Analyses of the occurrence of positive events, however, revealed a different picture: BAS was significantly related to both the frequency and importance of positive events $(b s=0.55$ and 0.11 , both $p s<.01$ ). That is, persons one standard deviation above the sample BAS mean reported experiencing on average 0.55 more positive daily events (frequency) and 0.11 greater importance ratings of positive events each day than persons of average BAS. Consistent with both Study 2 and our hypotheses, BIS did not significantly moderate positive events, and BAS did not moderate negative events. Thus, the differential exposure hypothesis was supported for positive events in Study 3.

\section{Ancillary Analyses}

Mediation. Because BAS predicted both PA and the occurrence of positive events, and because $P A$ and positive events covary, we reasoned that BAS may predict mean levels of PA through greater exposure to positive events. This is the mechanism specified by the differential exposure hypothesis. We conducted a mediational analysis to evaluate this hypothesis (Baron \& Kenny, 1986). Because this hypothesis is purely between-subjects, we aggregated each participants' event and affect data across the study's 7 days and used standard (OLS) hierarchical regression analysis.

Results of this analysis are displayed in Figure 1. The first requirement in demonstrating mediation is that the predictor variable be related to the outcome variable, that is, that BAS predicts PA. As in the HLM analyses, this effect was significant, $\beta=.24$, $p<.01$. The second requirement is to show that BAS predicts the putative mediator, positive events. Again, consistent with the HLM analyses, this result was significant for positive event frequency, $\beta=.20, p<.05$, and importance, $\beta=.22, p<.01$. The final requirement is that the mediator predicts the outcome variable and that this effect accounts for the direct effect between the predictor and outcome variable. Positive events significantly predicted PA $(\beta=.42, p<.001$, for frequency and $\beta=.49, p<.001$, for importance), and the direct effect from BAS to PA dropped considerably $(\beta$ dropped to $.16, p=.03$, with frequency and $.13, p=$

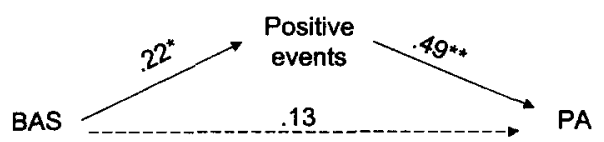

Figure 1. Mediational model using positive event importance. Numbers are standardized betas from the final step in multiple regression. The beta coefficient for the BAS-to-PA path was .24 in the unmediated model, which indicates a drop close to $45 \%$ of the relationship in the mediated model. $\mathrm{BAS}=$ behavioral activation system; $\mathrm{PA}=$ positive affect. $* p<.01 . \quad * * p<.001$.
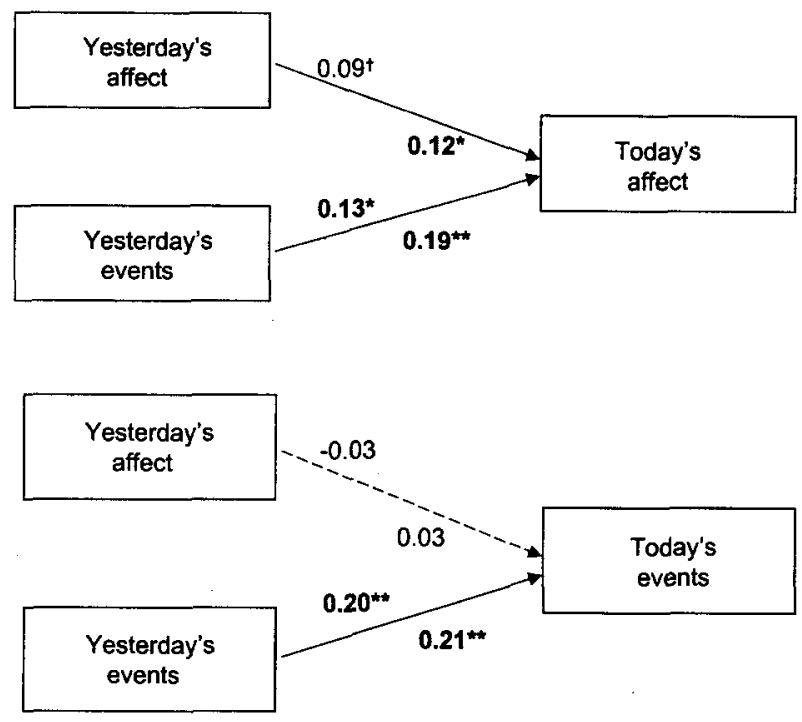

Figure 2. Predicting today's affect from yesterday's affect and yesterday's events (top), and predicting today's events from yesterday's affect and yesterday's events (bottom). Numbers on top of lines are relationships among Positive Affect and positive events; numbers below lines are relationships among Negative Affect and negative events. Pathways with broken lines indicate nonsignificant effects. $\dagger p<.07 .{ }^{*} p<$ .05. $* * p<.01$.

.06, with importance), which is evidence for partial mediation. Thus, BAS may influence PA, in part, through its relationship with positive events. Mediational analysis was not conducted for the BIS-negative events association, because BIS did not predict negative events.

"Affect $\rightarrow$ event" or "event $\rightarrow$ affect?" Establishing covariation between affect and events within days does not address the issue of causality, of course. Either direction is feasible. On days that people experience more NA, they may have more negative events, or perhaps they better remember the negative events that do occur. Conversely, and more in line with our theorizing, negative events may generate NA. These causal alternatives can be compared by examining the temporal sequence across days (West, Biesanz, \& Pitts, 2000). We constructed HLM equations that predicted today's events and affect from yesterday's affect and yesterday's events. If yesterday's events predict today's affect controlling for yesterday's affect, that is evidence that events generate affect. If yesterday's affect predicts today's events controlling for yesterday's events, this is evidence that affect leads to events. The certainty that each data record was completed on time in Study 3 justified these lagged-day analyses. The lower level equation for predicting today's NA was

$$
\begin{aligned}
\text { Today's } \mathrm{NA}_{i j}= & b_{0 j}+b_{1 j}\left(\mathrm{PA}_{i j}\right)+b_{2 j}\left(\mathrm{NA}_{i-1 j}\right) \\
& +b_{3 j}\left(\mathrm{NEGATIVE} \mathrm{EVENTS}_{i-1 j}\right)+r_{i j},
\end{aligned}
$$

where today's NA was predicted from today's PA (to partial out shared variance), yesterday's NA (Day $i-1$ ), and yesterday's negative events (Day $i-1$ ). The parallel equation for PA predicted today's PA from today's NA, yesterday's PA, and yesterday's positive events.

Figure 2 illustrates the results of this analysis. Coefficients for 
PA are displayed on top of the directional arrows, whereas coefficients for NA are displayed below the arrows. The top model shows that for both PA and NA, yesterday's events significantly predicted today's affect, even when yesterday's affect was controlled. Thus, a one-unit increase in average negative event importance predicted a $0.19(p<.01)$ increase in NA on the following day; the corresponding change for a one-unit increase in positive event importance on next day's PA was $0.13(p<.05)$.

To evaluate the alternative that yesterday's affect influences today's events, we constructed models parallel to Equation 9 by reversing the event and affect terms (i.e., predicting today's events from yesterday's events and yesterday's affect). These results are shown in the lower model of Figure 2. Yesterday's positive (above the arrow) and negative (below the arrow) events predicted today's negative and positive events, respectively, as expected. More conceptually important are the nonsignificant ( $p s>.40$ ) effects of previous day's NA and PA on today's events; these effects were virtually nil. Together, these analyses favor an event-to-affect causal chain over the reverse.

Meta-analyses. Despite the noncompliance issue and different methods of data collection, the results of Studies 2 and 3 were consistent. However, there were two discrepancies. In Study 2 (but not in Study 3) BIS significantly predicted average levels of PA, and in Study 3 (but not in Study 2) BAS significantly predicted positive events (both frequency and importance). Although Study 3 is probably more compelling given our compliance concerns in Study 2, it may nevertheless be useful to examine the robustness of these effects through meta-analysis. The combined $z$ for the effect of BIS on average PA was $-2.02, p<.05$ : Across studies, participants with higher BIS reported lower average PA than participants with lower BIS. The combined $z$ for the effect of BAS on average positive event frequency was $2.36, p<.01$; on average positive event importance, the combined $z$ was $3.13, p<$ .001 . Across studies, therefore, persons with higher BAS experienced more, and more important, positive events than persons with lower BAS, thus, supporting the differential exposure hypothesis for BAS.

Importance of events controlling for frequency. To assess whether BIS and BAS sensitivities influenced ratings of event importance regardless of their frequency, we computed "per-event impact" ratings by dividing the importance score for each day by the frequency score for that day and then averaging across days (separately for positive and negative events). The resulting value represents for each person the rated importance of events that occurred, irrespective of their frequency of occurrence. BAS sensitivity did not correlate with positive or negative event impact ratings ( $r \mathrm{~s}=.11$ and -.02 , respectively, $p \mathrm{~s}>.15$ ). Also, BIS did not predict impact ratings of positive events $(r=.10, p>.20$ ). However, in support of the reactivity hypothesis, BIS did predict the impact score of negative events, $r=.27, p<.01$. This indicates that, controlling for the number of events that occurred, people with high BIS scores rated negative events as more important. $^{10}$

\section{Discussion}

Study 3 replicated and extended the results of Study 2 . Negative events predicted NA again, and positive events predicted PA. BIS predicted average daily NA, and BAS predicted average daily PA. We also replicated the moderator effect for negative events and
NA, providing strong support for the reactivity hypothesis. In addition, the exposure hypothesis was supported for BAS, and its robustness was confirmed by meta-analysis of Studies 2 and 3. We further explored the BAS exposure result and found that positive events partially mediated the relationship between BAS and average PA. Most important, compliance with the daily protocol was substantially enhanced in Study 3, allowing lagged-day analyses to test alternative causal sequences. Yesterday's events predicted today's affect for both NA and PA, but an affect-to-events pathway was not supported.

\section{General Discussion}

This research examined three sources of variation in daily affect: daily events, dispositional BIS and BAS sensitivities, and the interaction between them. The within-person hypotheses spec-. ified that negative events would be related to NA and that positive events would be related to PA; all three studies found clear evidence supporting these hypotheses. "Crossover" effects between affect and the opposite-valence events were not expected, and no such effects were observed in Study 1, or for NA in all three studies. In Studies 2 and 3, however, negative events also covaried with daily PA, but this effect was substantially and significantly weaker than the hypothesized congruent-valence effect.

These results highlight the value of operationalizing daily mood in terms of discrete PA and NA terms. Had we used a measure that combines PA and NA, or had we looked only at one type of event (e.g., stressors), differential relationships of affect with positive and negative events would not have been identified. This finding extends earlier research pointing to the functional orthogonality of positive and negative affect (e.g., Cacioppo \& Gardner, 1999; Watson, 1988) by demonstrating not only that it is subjective experience (i.e., self-reports) of these affects that tends toward independence but also that they are functionally independent. That is, differential predictors point to the operation of distinct mechanisms, one producing positive affect in response to positive events and the other generating negative affect in response to negative events. Plausible candidates for these mechanisms include the BIS and BAS systems, which all people possess to some extent, over and above individual differences (Gray, 1987). Thus, positive events may activate the BAS system, leading to increases in PA. Negative events may activate the BIS system, leading to increases in NA.

An alternative explanation for our findings of distinct predictors of PA and NA is consistent with unidimensional models of affect (e.g., Barrett \& Russell, 1998). It is possible that processes influencing affect at one end of a bipolar dimension differ from those that influence affect at the other end of the dimension. The fact that we partialed out the opposite-valenced affect argues against this possibility. However, regardless of whether a unidimensional or a multidimensional model of affect is preferred, our results suggest

\footnotetext{
${ }^{9}$ We conducted parallel lagged-day analyses with data from Study 2, using only those participants who had completed all entries on time $(N=27)$. The magnitude of coefficients was similar to that reported for Study 3 (yesterday's positive events to today's $\mathbf{P A}=\mathbf{0 . 1 3}$, yesterday's negative events to today's $\mathrm{NA}=0.09$ ); however, these effects were not significant, likely because of the low power of this small sample. Also as in Study 3, coefficients predicting today's events from yesterday's affect were small and nonsignificant.

${ }^{10}$ We thank an anonymous reviewer for suggesting these analyses.
} 
that different processes account for variance in positively and negatively valenced affect.

Our main between-person hypotheses concerned individual differences in BIS and BAS sensitivity. As hypothesized, in both studies, people with higher BIS sensitivity reported higher levels of average NA, and people with higher BAS sensitivity reported higher levels of average PA. Thus, sensitivities of these two independent motivational systems are related to everyday affective experience. Previous studies had focused only on experimental stimuli tailor-made to activate the appropriate system and thereby elicit the expected emotion. It is important to establish that these effects extend to the sort of naturally occurring stimuli that arise spontaneously in normal activity.

The moderator (differential sensitivity) hypothesis received strong support in both studies for NA, indicating that people with higher BIS sensitivity tended to be more reactive to negative events, above baseline differences in average NA. In other words, a high-BIS person who experienced an above-normal day in the rated importance of negative events reported a greater increase in NA than an average- or low-BIS person who described their day's negative events in the exact same way. This pattern is consistent with Bolger and Schilling's (1991) results and may help explain why some people (i.e., those high in BIS) seem to experience the same stressors as more distressing.

We had also predicted that BAS sensitivity would moderate PA responses to positive events, but this was not found in either study. This result differs somewhat from Rusting and Larsen's (1997) finding that extraversion predicted susceptibility to an experimental positive mood induction (although they studied extraversion, which differs from BAS). Instead, Study 3 supported the differential exposure hypothesis: People with greater BAS sensitivity reported more positive daily events. Mediation analyses indicated that the main effect of BAS on PA was mediated by the occurrence of positive events. In other words, high BAS may predispose people to higher average PA, because high-BAS people experience positive events more frequently (and as more important), which in turn contributes to positive affect. Neither Study 2 nor Study 3 supported the differential exposure hypothesis for BIS. Prior studies have found that neuroticism was associated with reports of major life events; however, those studies examined major life stressors over longer time frames of recall (2-4 years) and used a different dispositional measure (Headey \& Wearing, 1989; Magnus et al., 1993).

The obtained differences between PA and NA may reflect differences in how BIS and BAS engage the environment. Whereas BIS sensitivity seems to influence NA through differential reactivity to negative events, the influence of BAS sensitivity appears to depend on differential exposure to positive events. No one seeks out negative events, of course, but in the course and conduct of everyday life, they do happen. The BIS system is designed to cope with negative events when they occur, and, therefore, its sensitivity for a given individual may determine the degree of emotional reaction. On the other hand, positive events may be less likely to occur without active initiation. BAS is by nature an approach system-it describes active pursuit of events with reward value and, therefore, may be more relevant to the pursuit of potentially positive (i.e., appetitive) events. In other words, we are arguing that negative events are more or less inevitable in normal activity, and the role of BIS is to regulate responses to them. Positive events, on the other hand, must be sought out, and BAS's role is to regulate that process. This speculation may help explain why differential reactivity was supported in the case of BIS, whereas BAS was better supported by differential exposure.

If this speculation is correct, the relative dearth of studies on positive events and appetitive processes relative to their negative and aversive counterparts, predicated perhaps on the assumption that they involve essentially parallel processes, may be misleading. A similar suggestion follows from research by Higgins and colleagues (reviewed by Higgins, 1998) on promotion and prevention self-regulatory styles. In their work, focus on creating desired positive end states (promotion) is associated with different feelings, behavioral strategies, and choices than is focus on the avoidance of undesired negative outcomes (prevention). Self-regulatory differences may be rooted in different motivational processes, such as activation and inhibition (see also Elliot \& Harackiewicz, 1996; Elliot, Sheldon, \& Church, 1997). The difference also highlights the value of examining such processes in everyday life, where activities often must be sought out, as a complement to the laboratory, where activities are usually imposed on participants by the experimental protocol.

Of course, many natural events have both positive and negative features that potentially activate either or both systems. Events for the present studies were chosen in part for their unambiguous valence. When an event's valence is mixed or ambiguous, motivational sensitivities may influence how the event is construed, thereby determining which system is activated and how the person reacts. For example, a job promotion might be seen as an opportunity to create more positive outcomes or as magnifying one's chances of failure. If so, the relative salience (i.e., chronic accessibility) of BIS and BAS may influence which features dominate the person's appraisal, so that high-BIS individuals would attend to the situation's potential aversive elements, whereas high-BAS individuals would orient to its potential rewards. High levels of both BIS and BAS may predispose conflicted reactions to ambiguous or complex events. This type of coordinated response between two independent systems has been demonstrated in attitude research (Cacioppo, Gardner, \& Berntson, 1997) and may also apply to everyday events.

This line of reasoning implies that people with more sensitive inhibition systems would rate negative events as more important and that those with more sensitive activation systems would rate positive events as more important. Our analyses of impact ratings of events examined importance ratings separately only for those events that did occur. BIS sensitivity was associated with increased ratings of the importance of negative events that did occur, but we found no such evidence for a relationship between BAS and positive event ratings. Perhaps a 0 -to- 4 scale of event importance may not be sensitive enough to capture individual differences in intensity ratings for positive events; or perhaps "importance" is not the dimension best suited for this distinction in positive events. In any case, the relationship between BIS and negative event importance provides some insight into possible processes underlying the reactivity hypothesis (i.e., interpretation of given events as more important).

The idea that BIS and BAS influence interpretation of environmental events is amenable to empirical investigation. Some events may inherently activate one system or the other (as our main 
effects for event valence imply). But when stimuli are ambiguous or contain both appetitive and aversive features, individual differences in the relative strength of BIS and BAS may direct interpretation in one or the other direction. Previous work suggests that BIS and BAS influence the amount of attention that potentially punishing and rewarding stimuli receive (Derryberry \& Reed, 1994); high-BIS people may orient attention quicker, and linger longer, on aversive stimuli, whereas high-BAS people may do the same for appetitive stimuli. Similar tendencies to focus on potential losses or gains in risk-taking situations may relate to BIS and BAS (Kahneman \& Tversky, 1979).

The possibility that BIS and BAS may influence interpretation of events is conceptually distinct from their influence on reactions to events. Even when events are interpreted similarly, reactions may differ. For example, the same event evaluation may produce stronger or weaker affective reactions in different individuals, depending on BIS or BAS sensitivity. Although in practice it may be difficult to distinguish interpretations of events and reactions to them, such work is necessary to delineate the processes by which dispositions and environmental stimuli combine to influence affect and behavior. The present research provided some support for this differentiation in that BIS moderated the strength of emotional reactions to equivalent levels of daily negative event importance. However, no two people in our studies experienced the exact same events, and it will be necessary to equate events to disentangle the two processes unambiguously.

\section{Temporal Sequence}

Our lagged-day analyses provided an important finding not shown in prior research. Prior day's events predicted current daily affect even when prior day's affect was controlled; in other words, events predicted change in affect from one day to the next. Affect, however, did not predict change in reported events from one day to the next. This was true for both positive and negative events and affect. Thus, the results are consistent with a model that posits events as the cause of daily affect and are not consistent with the alternative that affect causes events. A commonly cited limitation of daily events research is the inability to establish causality. Had we conducted only contemporaneous analyses, we would have been unable to choose between two alternative explanations: Do people in a given mood state seek out or recall more daily events consistent with their mood? Or, do positive or negative events lead people to congruent moods? The current lagged-day analyses provide clear relative support for the latter path. Perhaps, by virtue of their favorable or unfavorable impact on the person's wellbeing, events exert a direct effect on next-day affect, irrespective of same-day affect (which may fade overnight). The regular temporal sequence of many daily experience studies makes this method useful for comparing causal alternatives (Reis \& Gable, 2000; West et al., 2000), and we believe it would be valuable to capitalize on this method in future research.

\section{Limitations and Generalizability}

Several limitations should be noted. First, all three samples were college students. Although our findings are consistent with research using community samples (e.g., David et al., 1997), these studies should be replicated with nonstudents. Second, for practi- cal reasons, we created an events list that was as comprehensive as possible while still being concise; less common events that may influence daily affect were omitted. Our event list also featured relatively mundane daily events and excluded major life events. Future research might study a larger pool of events, including both major and minor types. Third, all diary entries were end-of-day assessments and as such probably were somewhat affected by retrospection. More important, because participants were instructed to complete diaries each evening, our data do not control possible time-of-day mood effects associated with personality (e.g., Rusting \& Larsen, 1998a). On the other hand, there is heuristic value in end-of-day data, given that days represent a natural unit for segmenting activity (Reis \& Gable, 2000).

Perhaps most disconcerting was participants' noncompliance with the recording schedule in Study 2 . Ironically, $97 \%$ of our participants reported little or no trouble running the study on time, a contention that clearly diverges from the time-stamp data. In that the justification for the diary method derives in part from timeliness, researchers should take appropriate precautions to ensure compliance with reporting schedules. Another limitation centers on the fact that self-report measures of BIS and BAS sensitivities are not direct measures of underlying physiological systems. However, Carver and White's (1994) BIS-BAS scales account for considerable variability in left- and right-sided mid-frontal asymmetry, respectively ( $r$ s $=.40$ and -.41 ; Sutton \& Davidson, 1997), which bolsters our confidence that the self-report measures are tapping the underlying physiological sensitivities, albeit imperfectly.

Finally, PA and NA have implications for understanding wellbeing that reach beyond measures of daily mood (Diener, 1996). For example, people with high levels of NA tend to report more physical symptoms (Watson \& Pennebaker, 1989), whereas people predisposed to PA tend to participate in higher quality social interactions (e.g., Berry \& Hansen, 1996; Zautra \& Reich, 1983). Research is needed to investigate how motivational dispositions influence more diverse markers of well-being such as effectiveness in work and social relations, depression, vitality, spirituality, and health-related activity. Also, because the PANAS assesses activated forms of positive and negative affect, research should examine relationships between events and lower arousal types of affect.

\section{Conclusion}

Consistent with Lewin's (1936) maxim that behavior depends on the interaction of person and environmental factors, the present set of studies provided evidence of the simultaneous operation of within-person and between-person processes as predictors of daily affect. Our findings support understanding the observed relationships between events and affect in terms of independent appetitive and aversive systems. Individual differences in sensitivities to positive and negative events appear to influence well-being through complex processes that involve people's tendencies to experience various types of events, their interpretation of those events, and their affective reactions to them.

\section{References}

Baron, R. M., \& Kenny, D. A. (1986). The moderator-mediator variable distinction in social psychological research: Conceptual, strategic, and 
statistical considerations. Journal of Personality and Social Psychology, 51, 1173-1182.

Barrett, L. F., \& Russell, J. A. (1998). Independence and bipolarity in the structure of current affect. Journal of Personality and Social Psychology, 74, 967-984.

Berry, D. S., \& Hansen, J. S. (1996). Positive affect, negative affect, and social interaction. Journal of Personality and Social Psychology, 71, 769-809.

Bolger, N., DeLongis, A., Kessler, R. C., \& Schilling, E. A. (1989). Effects of daily stress on negative mood. Journal of Personality and Social Psychology, 57, 808-818.

Bolger, N., \& Schilling, E. A. (1991). Personality and the problems of everyday life: The role of neuroticism in exposure and reactivity to daily stressors. Journal of Personality, 59, 355-386.

Bolger, N., \& Zuckerman, A. (1995). A framework for studying personality in the stress process. Journal of Personality and Social Psychology, 69, 890-902.

Bryk, A. S., \& Raudenbush, S. W. (1992). Hierarchical linear models. Newbury Park, CA: Sage.

Bryk, A. S., Raudenbush, S. W., \& Congdon, R. T. (1996). HLM: Hierarchical linear and nonlinear modeling with the HLM/2L and HLM3/L Programs. Chicago: Scientific Software International.

Butler, A. C., Hokanson, J. E., \& Flynn, H. A. (1994). A comparison of self-esteem lability and low trait self-esteem as vulnerability factors for depression. Jourmal of Personality and Social Psychology, 66, 166-177.

Cacioppo, J. T., \& Gardner, W. L. (1999). Emotion. Annual Review of Psychology, 50, 191-214.

Cacioppo, J. T., Gardner, W. L., \& Berntson, G. G. (1997). Beyond bipolar conceptualizations and measures: The case of attitudes and evaluative space. Personality and Social Psychology Review, 1, 3-25.

Carver, C. S. (1996). Emergent integration in contemporary personality psychology. Journal of Research in Personality, 30, 319-334.

Carver, C. S., \& White, T. L. (1994). Behavioral inhibition, behavioral activation, and affective responses to impending reward and punishment: The BIS/BAS scales. Journal of Personality and Social Psychology, 67, 319-333.

Clark, L. A., \& Watson, D. (1988). Mood and the mundane: Relations between daily life events and self-reported mood. Journal of Personality and Social Psychology, 54, 296-308.

Corr, P. J., Pickering, A. D., \& Gray, J. A. (1997). Personality, punishment, and procedural learning: A test of J. A. Gray's anxiety theory. Journal of Personality and Social Psychology, 73, 337-344.

David, J. P., Green, P. J., Martin, R., \& Suls, J. (1997). Differential roles of neuroticism, extraversion, and event desirability for mood in daily life: An integrative model of top-down and bottom-up influences. Journal of Personality and Social Psychology, 73, 149-159.

Derryberry, D., \& Reed, M. A. (1994). Temperament and attention: Orienting toward and away from positive and negative signals. Journal of Personality and Social Psychology, 66, 1128-1139.

Diener, E. (1996). Traits can be powerful, but are not enough: Lessons from subjective well-being. Joumal of Research in Personality, 30, 389-399.

Diener, E., \& Emmons, R. A. (1984). The independence of positive and negative affect. Joumal of Personality and Social Psychology, 47, $1105-1117$.

Diener, E., \& Lucas, R. E. (1999). Personality and subjective well-being. In D. Kahneman, E. Diener, \& N. Schwarz (Eds.), Well-being: The foundations of hedonic psychology (pp. 211-229). New York: Sage.

Elliot, A. J. (1997). Integrating the "classic" and "contemporary" approaches to achievement motivation: A hierarchical model of approach and avoidance motivation. In M. Maehr \& P. Pintrich (Eds.), Advances in motivation and achievement (Vol. 10, pp. 143-179). Greenwich, CT: JAI Press.

Elliot, A. J., \& Harackiewicz, J. M. (1996). Approach and avoidance achievement goals and intrinsic motivation: A mediational analysis. Journal of Personality and Social Psychology, 70, 968-980.

Elliot, A. J., Sheldon, K. M., \& Church, M. A. (1997). Avoidance personal goals and subjective well-being. Personality \& Social Psychology Bulletin, 23, 915-927.

Endler, N., \& Magnusson, D. (1976). Toward an interactional psychology of personality. Psychological Bulletin, 83, 956-974.

Fowles, D. C. (1994). A motivational theory of psychopathology. In W. D. Spaulding (Ed.), Nebraska Symposium on Motivation: Vol. 41. Integrative views of motivation, cognition, and emotion (pp. 181-238). Lincoln, NE: University of Nebraska Press.

Gable, S. L., \& Nezlek, J. B. (1998). Level and instability of day-to-day psychological well-being and risk for depression. Journal of Personality and Social Psychology, 74, 129-138.

Gable, S. L., \& Reis, H. T. (1999). Now and then, them and us, this and that: Studying relationships across time, partner, context, and person. Personal Relationships, 6, 415-432.

Gray, J. A. (1987). The psychology of fear and stress (2nd ed.). New York: Cambridge.

Gray, J. A. (1990). Brain systems that mediate both emotion and cognition. Cognition and Emotion, 4, 269-288.

Harmon-Jones, E., \& Allen, J. J. B. (1997). Behavioral activation sensitivity and resting frontal EEG asymmetry: Covariation of putative indicators related to risk for mood disorders. Journal of Abnormal Psychology, 106, 159-163.

Headey, B., \& Wearing, A. (1989). Personality, life events, and subjective well-being: Toward a dynamic equilibrium model. Journal of Personality and Social Psychology, 57, 731-739.

Higgins, E. T. (1998). Promotion and prevention: Regulatory focus as a motivational principle. In M. Zanna (Ed.), Advances in experimental social psychology (Vol. 30, pp. 1-46). San Diego, CA: Academic Press.

Holmes, T. H., \& Rahe, R. H. (1967). The social readjustment rating scale. Journal of Psychosomatic Research, 11, 213-218.

Jorm, A. F., Christensen, H., Henderson, A. S., Jacomb, P. A., Korten, A. E., \& Rodgers, B. (1999). Using the BIS/BAS scales to measure behavioural inhibition and behavioural activation: Factor structure, validity, and norms. Personality and Individual Differences, 26, 49-58.

Kahneman, D., \& Tversky, A. (1979). Prospect theory: An analysis of decision under risk. Econometrica, 47, 263-291.

Kanner, A. D., Coyne, J. C., Schaeffer, C., \& Lazarus, R. S. (1981). Comparison of two modes of stress measurement: Daily hassles and uplifts versus major life events. Journal of Behavioral Medicine, 4, $1-39$.

Lang, P. J. (1995). The emotion probe: Studies of motivation and attention. American Psychologist, 50, 372-385.

Langston, C. A. (1994). Capitalizing on and coping with daily-life events: Expressive responses to positive events. Journal of Personality and Social Psychology, 67, 1112-1125.

Larsen, R. J., \& Ketelaar, T. (1991). Personality and susceptibility to positive and negative emotional states. Journal of Personality and Social Psychology, 61, 132-140.

Larson, R. W. (1987). On the independence of positive and negative affect within hour-to-hour experience. Motivation and Emotion, 11, 145-156.

Lewin, K. (1936). Principles of topological psychology. New York: McGraw-Hill.

Litt, M. D., Cooney, N. L., \& Morse, P. (1998). Ecological momentary assessment (EMA) with treated alcoholics: Methodological problems and potential solutions. Health Psychology, 17, 48-52.

Magnus, K., Diener, E., Fujita, F., \& Pavot, W. (1993). Extraversion and neuroticism as predictors of objective life events: A longitudinal analysis. Journal of Personality and Social Psychology, 65, 1046-1053.

Marco, C. A., \& Suls, J. (1993). Daily stress and the trajectory of mood: Spillover, response assimilation, contrast, and chronic negative affectivity. Journal of Personality and Social Psychology, 64, 1053-1063. 
Meyer, G. J., \& Shack, J. R. (1989). Structural convergence of mood and personality: Evidence for old and new directions. Journal of Personality and Social Psychology, 57, 691-706.

Monteith, M. J. (1993). Self-regulation of prejudiced responses: Implications for progress in prejudice-reduction efforts. Journal of Personality and Social Psychology, 65, 469-485.

Moskowitz, D. S., \& Côté, S. (1995). Do interpersonal traits predict affect: A comparison of three models. Journal of Personality and Social Psychology, 69, 915-924.

Nezlek, J. B., \& Plesko, R. M. (in press). Day-to-day relationships among self-concept clarity, self-esteem, daily events, and mood. Personality and Social Psychology Bulletin.

Pickering, A. D., Corr, P. J., \& Gray, J. A. (1998). Interactions and reinforcement sensitivity theory: A theoretical analysis of Rusting and Larsen (1997). Personality and Individual Differences, 26, 357-365.

Reis, H. T., \& Gable, S. L. (2000). Event sampling and other methods for studying daily experience. In H. T. Reis \& C. M. Judd (Eds.), Handbook of research methods in social and personality psychology (pp. 190222). New York: Cambridge University Press.

Rosenthal, R., \& Rosnow, R. L. (1991). Essentials of behavioral research: Methods and data analysis (2nd ed.). New York: McGraw-Hill.

Rusting, C. L., \& Larsen, R. J. (1997). Extraversion, neuroticism, and susceptibility to positive and negative affect: A test of two theoretical models. Personality and Individual Differences, 22, 607-612.

Rusting, C. L., \& Larsen, R. J. (1998a). Diurnal patterns of unpleasant mood: Associations with neuroticism, depression, and anxiety. Journal of Personality, 66, 85-103.

Rusting, C. L., \& Larsen, R. J. (1998b). Personality and cognitive processing of affective information. Personality and Social Psychology Bulletin, 24, 200-213.

Rusting, C. L., \& Larsen, R. J. (1999). Clarifying Gray's theory of personality: A response to Pickering, Corr, and Gray. Personality and Individual Differences, 26, 367-372.

Schneider, W. (1988). Micro Experimental Laboratory: An integrated system for IBM-PC compatibles. Behavior Research Methods, Instrumentation, and Computers, 20, 206-217.

Seidlitz, L., \& Diener, E. (1993). Memory for positive versus negative life events: Theories for the differences between happy and unhappy persons. Journal of Personality and Social Psychology, 64, 654-664.

Suh, E., Diener, E., \& Fujita, F. (1996). Events and subjective well-being: Only recent events matter. Journal of Personality and Social Psychology, 70, 1091-1102.

Suls, J., Green, P., \& Hillis, S. (1998). Emotional reactivity to everyday problems, affective inertia, and neuroticism. Personality and Social Psychology Bulletin, 24, 127-136.
Sutton, S. K., \& Davidson, R. J. (1997). Prefrontal brain asymmetry: A biological substrate of the behavioral approach and inhibition systems. Psychological Science, 8, 204-210.

Tellegen, A. (1985). Structures of mood and personality and their relevance to assessing anxiety, with an emphasis on self-report. In A. H. Tuma \& J. D. Maser (Eds.), Anxiety and the anxiety disorders (pp. 681-706). Hillsdale, NJ: Erlbaum.

van Eck, M., Nicolson, N. A., \& Berkhof, J. (1998). Effects of stressful daily events on mood states: Relationship to global perceived stress. Journal of Personality and Social Psychology, 75, 1572-1585.

Watson, D. (1988). The vicissitudes of mood measurement: Effects of varying descriptors, time frames, and response formats on measures of positive and negative affect. Journal of Personality and Social Psychology, 55, 128-141.

Watson, D., \& Clark, L. A. (1994). Emotions, moods, traits, and temperaments: Conceptual distinctions and empirical findings. In P. Ekman \& R. J. Davidson (Eds.), The nature of emotion (pp. 89-93). New York: Oxford University Press.

Watson, D., \& Clark, L. A. (1997). Measurement and mismeasurement of mood: Recurrent and emergent issues. Journal of Personality Assessment, 68, 267-296.

Watson, D., Clark, L. A., \& Tellegen, A. (1988). Development and validation of brief measures of positive and negative affect: The PANAS scales. Journal of Personality and Social Psychology, 54, 1063-1070.

Watson, D., \& Pennebaker, J. W. (1989). Health complaints, stress, and distress: Exploring the central role of negative affectivity. Psychological Review, 96, 234-254.

Watson, D., Wiese, D., Vaidya, J., \& Tellegen, A. (1999). The two general activation systems of affect: Structural findings, evolutionary considerations, and psychobiological evidence. Journal of Personality and Social Psychology, 76, 820-838.

West, S. G., Biesanz, J. C., \& Pitts, S. C. (2000). Causal inference and generalization in field settings: Experimental and quasi-experimental designs. In H. T. Reis \& C. M. Judd (Eds.), Handbook of research methods in social and personality psychology (pp. 40-84). New York: Cambridge University Press.

Zautra, A. J., \& Reich, J. W. (1983). Life events and perceptions of life quality: Developments in a two-factor approach. American Journal of Community Psychology, 11, 121-132.

Received July 12,1999

Revision received January 12, 2000 Accepted February 1, 2000 